\title{
Differences in achievement between home language and language of learning in South Africa: Evidence from prePIRLS 2011
}

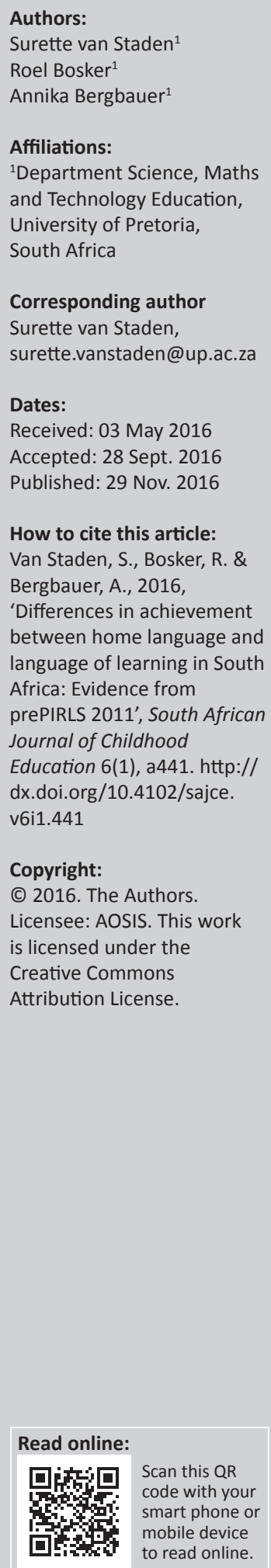

\begin{abstract}
This study utilised regression methods to explain Grade 4 reading literacy achievement taking into account discrepancies between the language of the test and home language for learners who participated in the South African preProgress in International Reading Literacy Study (prePIRLS) 2011. Grade 4 learners were tested across all 11 official languages. The language of testing did not always coincide with the learner's home language; therefore, prePIRLS 2011 test results reveal achievement for learners who in many cases did the test in a second or third language. Results from the current analyses show that testing in African languages predicts significantly lower results as compared to English, but that exponentially worse results by as much as 0.29 points lower of a standard deviation can be expected when the African language of the test did not coincide with the learners' home language. Findings from the current study provide evidence that African children stand to be disadvantaged the most when a strong mother tongue base has not been developed and when education for children between Grade 1 and 3 is only available through a medium of instruction other than the mother tongue. Evidence that exposure to a language that at least shares linguistic similarities to the home language could have a positive effect.
\end{abstract}

\section{Introduction}

Since becoming a democracy in 1994, the task of transforming from an inequitable system to that of a democratic society with equal opportunities for all its citizens became a priority in South Africa. Transformation needed to take place in a number of areas such as equal access to education, protection against discrimination and protection of language rights (Ahmed \& Sayed 2009). According to Motala (2006), central to this transformation task is the establishment of an education system based on principles of quality and equity in pursuit of democratic ideals. The transformation task has been met with a number of challenges, specifically in the provision of universal quality education for all (Motala 2001). Grave concerns with regards to low levels of learner achievement pervade research initiatives and educational debates. Persistently poor results across a number of cycles of international assessment programmes such as the Southern and East African Consortium for the Monitoring of Education Quality, the Trends in Maths and Science Study and the Progress in International Reading Literacy Study (PIRLS) provide evidence for a system under pressure to produce adequately literate and numerate learners. Evidence of poor performance has also formed the basis from which policy developments, changes and implementation have taken place. From a policy perspective, the Language in Education Policy (LiEP) has been instrumental in attempts to transform the South African education system to one of equity and equality.

This study is a secondary analysis of the prePIRLS 2011 South African Grade 4 data and seeks answers to the following questions:

1. What are the differences in reading literacy achievement of Grade 4 learners between home language and language of the test across the 11 official languages with English test language as reference category?

2. To what extent does the discrepancy between the language of the test and membership to a broader linguistic group contribute to reading achievement of Grade 4 learners when controlling for learner characteristics? ${ }^{1}$

1.Here, broader linguistic groups refer to the reduction of the 11 official languages to five language groups based upon linguistic similarities. These are Afrikaans, English, Nguni (consisting of isiNdebele, isiZulu, isiXhosa, SiSwati and Xitsonga), Sepedi (consisting of Sepedi, Sesotho and Setswana) and Tshivenda. The 11 individual languages were reduced to language groups in order to increase robustness and validity of analyses with greater sample sizes based on the close relatedness of languages within groups.

Note: Some of the writing and research of this article is based on work previously published by Surette van Staden. Please see link to previous published work: http://www.rw.org.za/index.php/rw/article/view/45 
3. What is the effect on literacy achievement of the teacher switching to other languages in order to facilitate understanding during the lesson?

4. What is the effect on literacy achievement of the learner switching to other languages to express their understanding of what was taught?

The following sections describe the complexity of the South African language landscape and the intentions of the LiEP and the challenges with its implementation. The discussion concludes with reflections on codeswitching practices as attempts to address linguistically complex classrooms and debates between the use of English as medium of instruction and African languages and implications thereof.

\section{Complexities with regard to the LiEP and its implementation}

LiEP (Department of Education, Government gazette no. 18546, December 19, 1997) attempts to promote language equity and quality education in all 11 official languages. In the preamble of this policy document ('The South African National Educational System Language Policy' 1997), it is recognised that the cultural diversity of South Africa is a national asset (Mothata \& Lemmer 2002). With this asset in mind, the LiEP aims at promoting multilingualism and the development of all 11 official languages specified in the South African Constitution. According to South African Census 2011 data, isiZulu is the most widely spoken language in South African households (22.7\%) followed by isiXhosa $(16.0 \%)$, Afrikaans (13.5\%) and English (9.6\%) as the predominant languages. Sotho languages include Sepedi, as spoken by $9.1 \%$ of households, Setswana $(8 \%)$ and Sesotho (7.6\%). Smaller languages include Xitsonga (4.5\%), SiSwati $(2.6 \%)$, Tshivenda $(2.4 \%)$ and isiNdebele $(2.1 \%)$. Finlayson and Madiba (2002) discuss the constitutional framework, which provides for all these languages to be developed, in particular African languages. These authors argue that the question is not whether these languages should be developed, but how within the shortest possible time to a point where they can express concepts that are already in existence in Afrikaans and English. The LiEP's underlying principle is to maintain home language(s), while providing access to the effective acquisition of additional languages. Therefore, the Department of Education follows an additive approach to promoting bilingualism from a mother tongue base. Edwards and Ngwaru (2011) refer to this mother tongue-based bilingual education, with the stipulation in the policy that South African learners receive instruction at school in their home language until they reach Grade 3. In Grade 4, the language of instruction changes to mostly English or Afrikaans, a second language for more than $80.0 \%$ of learners who come from African language backgrounds. However, these learners may continue to receive reading instruction in the language of instruction of the first 3 years of schooling (Howie, Venter \& Van Staden 2008). According to Ncoko, Osman and Cockroft (2000), the LiEP allows schools to determine their own language policy in consultation with parents and the community. It states that all learners have the right to be taught in their mother tongue where practical and reasonable. Mothata and Lemmer (2002) state that the LiEP should operate from a point of equity, practicality and the need to redress discriminatory laws and practices.

Despite being well intended, the implementation of the LiEP has thus far been ineffective. According to Howie et al. (2008), the policy fails to recognise the complexity of a situation where many schools teach learners in Grade 1, 2 and 3 in a language of learning that is nonetheless different from what is spoken at home. Therefore, learners do not necessarily receive mother tongue education in the first 3 years of schooling as stipulated by the LiEP (Van Staden 2010). Most learners go on to learn in a second language from Grade 4 onwards when the language of instruction changes yet again. Instruction then takes place either in English, a language spoken by fewer than $10 \%$ of the population at home, or in Afrikaans. While the intention is to accommodate learners in an additive bilingual model, the reality is that the language system is one of immersion, where a language that is not the language of the larger society is used as a medium of instruction (Admiraal, Westhoff \& De Bot 2006). The challenge remains to provide quality education to a multicultural learner population who speak 11 different languages where there is currently no evidence that a solid mother tongue foundation forms the basis for second-language acquisition. Brock-Utne (2007) supports the argument of lack of a solid mother tongue by stating that millions of children enter school without knowing the language of instruction, while formal schooling also takes place in a language they neither speak nor understand. Grant and Wong (2003) take the view that the prospect for long-term educational parity between English second (or even third language) learners and native English speakers is at best questionable because of failure by language minority learners to attain grade-level competence in reading, a pattern that often persists well beyond high school. Desai (2001) refers to an 'incomprehensible education' to describe this situation where most children from African language backgrounds are not taught through their primary languages. According to Carlo et al. (2004) English second-language learners' poor reading comprehension achievement is often because of a low vocabulary in English. Lack of knowledge of middle- and low-frequency words impede comprehension of texts, which in turn is detrimental to learning new word meanings from exposure to such words during reading. Carlo et al. (2004) describe the effect as reciprocal, where grater vocabulary knowledge makes comprehension easier and wider reading generates larger vocabulary, a cycle that is likely to be perpetuated by learners who learn in a language other than their primary language. Droop and Verhoeven (2003) are of the opinion that children's first-language word-decoding skills shift from accessing word representations via phonic components to accessing the representations directly. In this way, word recognition and reading comprehension are strongly related during the initial stages of learning to read and that this relationship weakens as language increases in importance. However, for second-language learners, the processes between the phonics, graphemic and semantic 
nodes are weaker than for first-language learners. Limited exposure to the second language may lead to qualitatively weaker word representations and slower and less accurate reading. Koda (2007) echoes the views of Droop and Verhoeven (2003) by stating that second-language reading differs markedly from first-language reading simply because it involves two languages in virtually all of its operations. Koda (2007) highlights the inherent difficulties when attempting to compare first-language to second-language learners: secondlanguage learners often encompass a wide range of learners from different backgrounds, ages and diverse first-language backgrounds. Cognitive and linguistic resources accessible to second-language learners vary considerably more than those available to first-language learners; therefore, any comparison between first-language and second-language learners have to take into account what learners have learnt through prior literacy experience, how these experiences have been incorporated into second-language reading and how such incorporation affects second-language reading development.

In South Africa, the complexity between first- and secondlanguage learners has been described by Pretorius (2002), who makes the argument that in a multilingual society, such as South Africa, the reading problem is often masked by the language problem. In this regard, Pretorius (2002) makes the following observation:

Because so many of the learners study through the medium of a language that is not their primary language, it is generally assumed that poor academic performance stems from poor additional language proficiency. Such a relationship obviously does exist, but is more complex than it appears and is one that needs to be more closely examined. For instance, when learners have difficulty reading to learn, it is often argued that their comprehension problems stem from limited language proficiency. This reflects an underlying assumption that language proficiency and reading ability are basically 'the same thing'. If this were so, then all mother-tongue speakers should automatically be good readers in their mother-tongue. This is patently not so. (p. 174)

Heugh (2002) stated that the LiEP in South Africa implies that other official languages are used as languages of instruction alongside English. This implication means that textbooks in languages other than English should become available and systematic development should take place in the area of terminology and translation. Despite these ideals, Edwards and Ngwaru (2011) state that language infrastructure in South Africa is still dominated by English books. Learners in African language classrooms predominantly use textbooks as a main (and often only) resource. Despite efforts by national and provincial book campaigns (such as 'Run home to read') 'real' books for reading and enjoyment and other supplementary materials remain scarce in African languages. Such materials in African languages are often difficult to find outside major cities, are expensive, and the money spent by departments of education on 'real' books in African languages remains limited (Edwards \& Ngwaru 2011). Issues such as the importance of oral culture, lack of disposable income and low levels of literacy have to be borne in mind when reflecting on the effectiveness of the LiEP thus far in developing African language infrastructure.
Kamwangamalu (2003) echoes other research in stating that the policy failed to work for all languages, a sentiment also voiced by Taylor (2007), who states that despite the recommendation from government for children to be taught in their mother tongue, African children specifically, who do not only constitute the majority but also the poorest fractions of society, are largely schooled in English from Grade 4 onwards, a second or third language to most of these children. As a result, goals to promote the use of the indigenous African languages have not been reached and Kamwangamalu (2003) observes a language shift away from indigenous African languages to English, specifically in urban black communities. He goes on to cite evidence that learners regard English as the language of learning:

without which one 'can do nothing', 'cannot get a job', 'cannot succeed in life'. Zulu is not associated with any of these attributes. On the contrary, the purpose of learning Zulu is to keep the language and the culture it embodies alive, so that the children did not forget their roots. (p. 236)

Nyika (2009) adds his voice to the concerns that little progress has been made towards implementing a multilingual policy and that despite documented merits thereof, resistance to mother tongue education persists. The use of English as preferred language then also inevitably comes into question, as supported by Bergbauer (2015), who states that:

English-language schools most likely yield a premium for African learners, and affirms common wisdom of African mother tongue speakers who select into English-language schools in search of higher school quality. (p. 48)

In attempts to achieve a range of cognitive and affective teaching and learning goals, teachers in South African classrooms make use of codeswitching. Ncoko et al. (2000) refer to codeswitching as the use of two or more languages in the same conversation. According to these authors, codeswitching indicates skilled performance and language proficiency and should be used as a valuable communicative tool in the classroom if well-structured and organised. Codeswitching results from the interconnectedness of languages and attempts to isolate and separate languages perpetuate a myth of languages as 'hermetically sealed units' (Ncoko et al. 2000). However, Probyn (2009) warns that codeswitching is neither generally accepted as a legitimate classroom strategy nor sanctioned in teacher training.

Probyn (2009) provides additional background to the debates around codeswitching by stating that learners living outside urban areas often do not acquire the threshold level of English proficiency to enable them to actively engage with the curriculum. In 2001, Probyn already spoke of the growing tension between English and mother tongue as medium of instruction when describing the reality of South African classrooms in the following way: Classrooms often offer a mix of English and mother tongue where teachers deliver chunks of English content, but switch to mother tongue for purposes of elaboration and discussion. In this way, learners hardly ever engage in active language production or meaningful discourse in English. Additionally, such practices set in place patterns of rote learning and dependency on the 
teacher as 'keeper of knowledge', which is likely to continue to secondary school and have implications for learners' cognitive development. De Wet (2002) too reports her observations where teachers often lack English proficiency that is necessary for effective teaching in support of English language learning and effective teaching of literacy skills across the curriculum. In imitating teachers, learners then perpetuate patterns of incorrect pronunciation, grammar and vocabulary. According to Probyn (2001), the medium of instruction becomes a barrier to effective learning and teaching and any ideals of constructivist notions of teachers and learners collaborating in creating meaning are severely compromised.

\section{South Africa's participation in the Progress in International Reading Literacy Study}

South African learners' poor performance in reading literacy was first evidenced by the PIRLS 2006 results. Run under the auspices of the International Association for the Evaluation of Educational Achievement (IEA), PIRLS is administered in 5-year cycles and requires the assessment of learners who have had 4 years of schooling (Mullis et al. 2007). For most countries, this requirement translates to Grade 4 learners. PIRLS 2006 aimed to describe trends and international comparisons for the reading achievement of Grade 4 learners. It also focused on learners' competencies in relation to goals and standards for reading education, the impact of the home environment and how parents foster reading literacy, the implementation of the curriculum, time and reading materials for learning to read in schools and classroom approaches to reading instruction (Mullis et al. 2004).

For purposes of PIRLS 2006, the South African study not only assessed a first population of Grade 4 learners but also included a second population of Grade 5 learners as a national option within the study (Howie et al. 2009). South African Grade 5 learners achieved the lowest score of the 45 participating education systems of 302 (standard error [SE] $=5.6)$. Grade 4 learners achieved on average 253 points $(\mathrm{SE}=4.6)$. Average achievement for both these grades was well below the fixed international reference average of 500 points, with 2 and 2.5 standard deviation points, respectively.

Evidence of poor learner performance became evident again in PIRLS 2011. For purposes of this cycle, the South African study assessed a Grade 5 population in order to develop trends from PIRLS 2006 to PIRLS 2011. However, to assess Grade 4 learners, South Africa opted to participate in the prePIRLS 2011. prePIRLS 2011 offers developing countries the opportunity to test reading literacy at an easier level than PIRLS while utilising the same conception of reading literacy. Mullis et al. (2012) describe prePIRLS 2011 as a less difficult version of PIRLS, which allows developing countries to assess children's reading comprehension with shorter texts, easier vocabulary, simpler grammar and less emphasis on higher-order reading skills. prePIRLS 2011 was designed to test basic reading skills that are prerequisites for success in PIRLS (Mullis et al. 2012). South African Grade 4 learners were assessed across all 11 official languages.
Even when administering an easier assessment, prePIRLS 2011 results point to continued underperformance by South African learners with little evidence of improved reading literacy scores. The prePIRLS 2011 study results revealed that South African Grade 4 learners obtained an average score of $461(\mathrm{SE}=3.7)$, the lowest reading achievement score in comparison with the international centre point of 500 (Mullis et al. 2012). Analyses of the results show that South African Grade 4 learners mostly have the ability to locate and retrieve explicitly stated detail in a literary text and the ability to locate and reproduce explicitly stated information from an informational text (Mullis et al. 2012). At this level, the majority of South African Grade 4 learners are unable to make straightforward inferences and integrate ideas and evidence across texts or interpret events to provide reasons, motivations or feelings with full text-based support. The gravity of these findings are exacerbated by the fact that these learners were not only tested with an easier assessment but also in the language (any one of 11 official languages) in which they had been receiving instruction during the Foundation Phase of schooling in accordance with the LiEP.

\section{Methods \\ Participants}

prePIRLS 2011 makes data available for a nationally representative sample of 15744 Grade 4 learners from 342 schools in South Africa. The sample consisted of 7548 girls and 8196 boys. Learners were assessed across all 11 official languages and the assessment was administered in the Language of Learning and Teaching to which they were exposed between Grade 1 and 3. This means that learners were not automatically tested in their home language, but rather in the language they were exposed to during their first years at school. Tables 1 and 2 show the number of learners assessed in prePIRLS 2011 by language of the test.

TABLE 1: Number of Grade 4 prePIRLS 2011 students tested by language.

\begin{tabular}{lc}
\hline Language & $\boldsymbol{N}$ \\
\hline Afrikaans & 1463 \\
English & 2205 \\
isiNdebele & 1393 \\
isiXhosa & 1090 \\
isiZulu & 1209 \\
Sepedi & 1099 \\
Sesotho & 1431 \\
Setswana & 1293 \\
SiSwati & 2186 \\
Tshivenda & 1187 \\
Xitsonga & 1188 \\
\hline
\end{tabular}

Source: Howie et al. (2012)

TABLE 2: Number of Grade 4 prePIRLS 2011 students tested by language group.

\begin{tabular}{lc}
\hline Language & $\boldsymbol{N}$ \\
\hline Afrikaans & 1463 \\
English & 2205 \\
$\begin{array}{l}\text { Nguni (isiNdebele, isiXhosa, isiZulu, } \\
\text { SiSwati and Xitsonga) }\end{array}$ & 7066 \\
Sotho & 3823 \\
Tshivenda & 1187 \\
\hline
\end{tabular}




\section{Data collection instruments}

\section{Achievement tests}

The prePIRLS 2011 reading assessment consisted of two types of texts, namely reading for literary experience (or literary texts) and reading to acquire and use information (or informational texts). Reading texts were followed by a number of multiple-choice questions and open-response questions. Open-response questions were to a maximum of three points. All questions corresponded to any one of the four types of reading comprehension processes, namely (1) focus on and retrieve explicitly stated information, (2) making straightforward inferences, (3) interpret and integrate ideas and information and (4) examine and evaluate content, language and textual elements (Mullis et al. 2009). Reporting of reading achievement results in prePIRLS 2011 are presented in terms of Plausible Values that point to average achievement above or below the fixed international centre point of 500 .

\section{Background questionnaires}

Grade 4 learners, their parents, teachers of the Grade 4 learners and school principals responded to background questionnaires that addressed a wide range of topics related to reading on aspects such as reading behaviour, attitudes, the teaching of reading and school organisation. Learner and parent questionnaires were administered in all 11 official languages to accommodate learners and parents optimally, while teachers and school questionnaires were administered in English only.

\section{Selection of variables}

Variables were selected from the prePIRLS 2011 learner and teacher questionnaires. Learner sex (variable ITSEX), age (variable ITBIRTHY) and home language (variable ITLANG) were taken from the learner questionnaire to control for learner characteristics. To additionally control for learner background, an asset scale was created using multiple correspondence analysis (MCA) ${ }^{2}$ from the variable ASBG05A-N by analysing the pattern of relationships of the possessions learners reported to have in the home. These items included a computer, study desk, books of your own, your own room, Internet connection, daily newspaper, own cell phone, calculator, dictionary, electricity, running tap water, television, video/CD/DVD player and waterflush toilets.

Learners were asked to indicate their home language (or the language they speak most at home) in the learner questionnaire (variable ASBG03). This was compared to the language in which the learners were tested. The discrepancy between the language of the test and the home language (or language spoken most at home as reported by learners) was calculated for each of the 11 official languages individually. A discrepancy was also calculated between the language of the test and the language group to which a learner belonged. In order to do this, the language of the test was reduced to five language groups, namely the Afrikaans group, the English group, the Nguni group (consisting of isNdebele, isiXhosa, isiZulu, SiSwati and Xitsonga), the Sotho group (consisting of Sepedi, Sesotho and Setswana) and the Tshivenda group.

To answer research questions around the possible extent of the effect of codeswitching, two variables were taken from the teacher questionnaire, namely 'Do you ever change to another language to support understanding when teaching your Grade 4 class?' (variable ATNR22C) and 'Do you allow learners to use another language to explain their understanding of what has been taught?' (variable ATNR22D). Both these variables formed part of the national option questions posed to teachers in the South African prePIRLS 2011 questionnaire.

\section{Procedure}

Background data are available for 15744 Grade 4 learners and 416 teachers Grade 4 learners. The International Database (IDB) Analyser was used for the purposes of generating descriptive statistics for the variables used in this investigation. The IDB Analyser uses the Statistical Package for the Social Sciences (SPSS) as platform and was developed by the IEA's Data Processing and Research Centre. It was developed specifically to combine and analyse data from large-scale data sets such as those designed for PIRLS and prePIRLS 2011.

The prePIRLS sample is nationally representative with $100 \%$ coverage (Mullis et al. 2012). Sampling used explicit stratification by Grade 4 school type and language of instruction and implicit stratification by school type (one language, two languages and multi-language) and province. In the bilingual stratum, two classrooms per school were sampled (one classroom per language). Very small schools and schools of languages other than the 11 official languages were excluded, while no within-school exclusions happened. Additionally, probability weights account for lower learner heteroscedasticity through survey design. Frequency weights compensate for school clustering. Hence, with regression analysis clustered on school level, robust SEs are yielded.

For econometric analysis, education outcomes are determined by the vectors language, school, family and learner variables. OLS is calculates an education production function as follows:

$$
\begin{aligned}
& \text { test score }=\alpha+\beta \text { LANGUAGE }_{i}+\gamma \mathrm{SCHOOL}_{j}+ \\
& \delta \mathrm{FAMILY}_{k}+\mu \mathrm{LEARNER}_{l}+\varepsilon
\end{aligned}
$$

The dependent variable test score is measured in plausible values in prePIRLS 2011. By survey design, five randomly assigned booklets yield similarly distributed plausible values of reading skills according to the Item Response Theory. The first plausible value is chosen as dependent variable, while the other four plausible values are used for robustness checks. Test language $i$ is either English or one of the African languages linked to one or another tier of South Africa's bi- 
modal education quality. School variables $j$ include schoollevel learning inputs such as provision of a library or location of the school. Family attributes $k$ refer to wealth measured by an asset index, parental attributes and home language. Individual learner characteristics encompass gender, age and some non-conventional attributes.

Higher-quality schooling may emerge from endogeneities rendering school choice non-random. International empiric research suggests a positive relation of higher school quality and higher socio-economic status of learners exemplified by parental income, occupation and education (Hauser 1994; Scott-Jones 1984). Learners of higher socio-economic status are suspected to self-select into higher-quality schools in search for higher learning outcomes. Furthermore, more apt learners may opt for higher-quality schools. Both endogeneities violate OLS assumptions of simple random sampling of Learners' school choice. Hence, error terms may be correlated. Evans \& Schwab (1995), Andrabi et al. (2011) and Deming et al. (2014) justify the use of OLS. Hence, we control for socio-economic family characteristics and school inputs contributing to non-random school choice.

To control for learner characteristics, a learner asset scale and a school asset scale, learner age, sex and home language were used as controls for the regression analysis using Stata version 13.0 software to test for significant effects of discrepancy between:

- Language of the test and home language. (Afrikaans, English, isiNdebele, isiXhosa, isiZulu, Sepedi, Sesotho, Setswana, SiSwati, Tshivenda and Xitsonga).

- Language of the test and membership to one of five groups of languages. (Afrikaans, English, Nguni, Sotho and Tshivenda).

Codeswitching variables as evidenced by teachers who make use of the practice or who allow learners to make use of the practice as additional variables to the model.

The current study takes learner characteristics, such as age, sex (coded as the effect of being female), asset scale and language of the test into account in order to isolate the effect of discrepancies for those learners who wrote in the best performing languages, namely Afrikaans and English. The overall plausible values from the prePIRLS 2011 data were used as outcome variable.

\section{Results}

\section{Summary of descriptive statistics for variables used}

prePIRLS 2011 results place South African Grade 4 learners substantially below the international centre point of 500 at 461 (SE = 3.7). In South Africa, 48\% of the prePIRLS 2011 sample was girls and the average age of learners who participated in prePIRLS 2011 was 10.5 years. In prePIRLS, far fewer learners in South Africa can be categorised as living in homes with many resources than internationally. Two percent of South African learners had many resources at home and most of these learners come from the groups assessed in Afrikaans or English, in addition to a few assessed in isiNdebele, siSwati, Tshivenda and Xitsonga.

In total, $66.5 \%$ of learners did the prePIRLS 2011 test in their home language with $22.6 \%$ of learners doing the test in a language different from their home language $(10.9 \%$ of data were missing). Table 3 provides information on reading literacy achievement per language and rank orders the percentage of learners per language where differences between home language and language of the test are observed from the largest percentage where language of the test and home language coincided to the smallest percentage.

Figure 1 indicates the difference in achievement for learners who did the prePIRLS 2011 test in their home language compared to those learners who did the test in a language different from their home language. In most languages, the achievement was substantially higher when learners wrote in their home language with the exception of Afrikaans, isiZulu and Sepedi where there was no significant difference.

Figure 1 indicates that the largest difference in achievement is observed for learners who did the prePIRLS 2011 test in English when it was not their home language. A difference of 80 points means a 2-year difference in educational terms for those children who wrote the test in English in home language compared to those children who wrote the test in English when it was not home language.

TABLE 3: prePIRLS 2011 achievement per language and percentage coincidence of home language and test language.

\begin{tabular}{|c|c|c|c|c|}
\hline Test language & $N$ & Mean score & SE & $\begin{array}{l}\% \text { of students: Language of the test same as home language } \\
\text { (arranged from highest to lowest) }\end{array}$ \\
\hline Afrikaans & 1463 & 525 & 9.9 & 90 \\
\hline isiXhosa & 1090 & 428 & 10.4 & 94 \\
\hline isizulu & 1209 & 442 & 9.3 & 92 \\
\hline Tshivenda & 1187 & 395 & 7.6 & 89 \\
\hline SiSwati & 2186 & 451 & 5.8 & 88 \\
\hline Xitsonga & 1188 & 406 & 8.4 & 87 \\
\hline isiNdebele & 1393 & 435 & 5.4 & 77 \\
\hline Sesotho & 1431 & 425 & 7.2 & 76 \\
\hline Setswana & 1293 & 428 & 4.9 & 74 \\
\hline Sepedi & 1099 & 388 & 7.4 & 54 \\
\hline English & 2205 & 530 & 10.1 & 33 \\
\hline
\end{tabular}

$\mathrm{SE}$, standard error. 


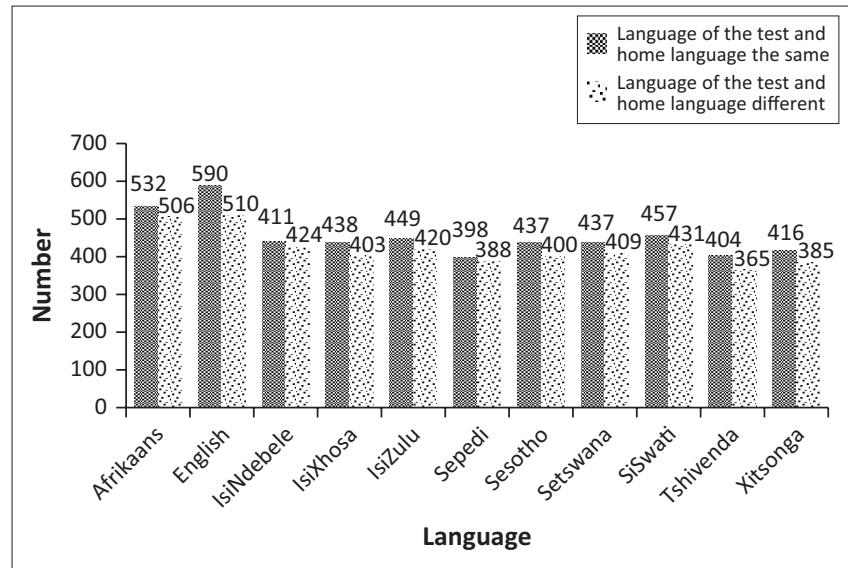

FIGURE 1: South African Grade 4 student performance by test language in the same or different language to their home language.

A majority of $83 \%$ of teachers of Grade 4 learners indicated that they switch to other languages when teaching their class how to read/reading. Similarly, a majority of $79 \%$ of teachers of Grade 4 learners indicated that they allow their learners to express themselves in languages other than the language of instruction. It has to be noted that questions regarding codeswitching practices were categorical and asked of teachers only whether they engaged in such practices or not. The questions did not ask when codeswitching was mostly applied (e.g. to explain content) or to which languages teachers and learners were most likely to code switch to.

\section{Regression results}

Regression analysis was used to determine the strength of evidence for the effect of the difference in reading achievement when tested in home language compared to being tested in a language other than home language on reading achievement as response or dependent variable.

The first research question asked: What are the differences in reading literacy achievement of Grade 4 learners between home languages and languages of the test across the 11 official languages with English test language as reference category?

Table 4 provides regression results for each of the languages. English test language is used as reference group against which all comparisons are made.

Table 4 indicates significant coefficients in each of the language scenarios except for Afrikaans test language for which there is no significant difference when compared to English test language. Of interest to see is that Afrikaans home language and African language performance (both test language and home language) all indicate significant lower expected achievement in comparison to English test language. Achievement for Grade 4 learners who were tested in African languages is adversely worse for those learners by test language - these coefficients would indicate performance for learners who were tested in an African language when that language was not their home language. So, for example,
TABLE 4: Model results by students who wrote in the language of the test.

\begin{tabular}{|c|c|c|c|}
\hline Factor: Constant & 604.4: Coefficient & 12.04: SE & $t$ \\
\hline Female students & 26.38 & 1.38 & $19.16 * * *$ \\
\hline Student age & -8.02 & 0.86 & $-9.33 * * *$ \\
\hline Student asset scale & 4.58 & 0.47 & $9.54 * * *$ \\
\hline Student asset scale squared & -0.264 & 0.27 & -0.96 \\
\hline School assets & 28.88 & 2.75 & $10.50 * * *$ \\
\hline Afrikaans test language & -0.0126 & 11.03 & -0.00 \\
\hline Afrikaans home language & -33.27 & 7.78 & $-4.28 * * *$ \\
\hline IsiNdebele test language & -63.55 & 8.87 & $-7.16 * * *$ \\
\hline IsiNdebele home language & -30.30 & 6.50 & $-4.66 * * *$ \\
\hline IsiXhosa test language & -38.60 & 11.47 & $-3.37 * * *$ \\
\hline IsiXhosa home language & -30.69 & 6.22 & $-4.93 * * *$ \\
\hline IsiZulu test language & -40.91 & 12.01 & $-3.41 * * *$ \\
\hline IsiZulu home language & -35.05 & 7.35 & $-4.77 * * *$ \\
\hline Sepedi test language & -91.48 & 10.83 & $-8.45 * * *$ \\
\hline Sepedi home language & -41.03 & 7.66 & $-5.36 * * *$ \\
\hline Sesotho test language & -50.49 & 9.49 & $-5.32 * * *$ \\
\hline Sesotho home language & -35.64 & 6.03 & $-5.91 * * *$ \\
\hline Setswana test language & -65.11 & 8.71 & $-7.48 * * *$ \\
\hline Setswana home language & -27.47 & 7.31 & $-3.76 * * *$ \\
\hline SiSwati test language & -62.74 & 8.34 & $-7.52 * * *$ \\
\hline siSwati home language & -22.41 & 7.29 & $-3.07 * * *$ \\
\hline Tshivenda test language & -78.90 & 13.98 & $-5.64 * * *$ \\
\hline Tshivenda home language & -22.95 & 10.96 & $-2.09 * * *$ \\
\hline Xitsonga test language & -71.48 & 10.97 & $-6.52 * * *$ \\
\hline Xitsonga home language & -34.65 & 8.38 & $-4.13 * * *$ \\
\hline
\end{tabular}

$\mathrm{SE}$, Standard error.

***, Indicates $p<0.01$

Table 3 illustrates that Learners who had Tshivenda as home language can be expected to achieve 22.95 (10.96) points lower when compared to learners who were tested in English. Learners who were tested in Tshivenda can be expected to achieve as much as 78.90 (13.98) points lower when compared to learners who were tested in English, an already heterogeneous group of learners. This same pattern of expected achievement is observed across all the African languages and would therefore suggest African home and test language already predicts significantly lower results as compared to English.

In terms of the background variables that were controlled for in Table 3, gender is a significant variable in favour of female learners who can be expected to achieve 26.38 (1.38) points more than male learners. For each year increase in learner age while remaining in Grade 4, reading achievement decreases with $8.02(0.86)$ points. In addition, learners with more assets at home significantly increases reading achievement scores by 4.58 points (0.47), similarly to school assets that significantly increase reading achievement scores by 28.88 points (2.75). The learner asset scale was squared to illustrate the nonlinear effect, where it can be expected that after a certain threshold of assets, test score gains level out. In the current model, this squared value was not statistically significant. The model presented in Table 3 accounts for 39\% of the variance in the data.

The second research question in the current study asked to what extent does the discrepancy between the language of the test and membership to a broader linguistic group 
contribute to reading achievement of Grade 4 learners when controlling for learner characteristics. Table 5 provides the model results for this discrepancy.

The discrepancy dummy turns one, when home and test language do not coincide. The dummy remains zero when home and test languages coincide. Hence, regression results suggest a highly significant and relatively large disadvantage on test score averages of 28.94 points, when learners take the test in another language than their home language. Adding the discrepancy dummy alters the other variables' coefficients, for example, the home language coefficients for isiZulu, Sesotho and isiXhosa show a considerable decrease. This decrease is because of those learners who were not tested in their home language and are now captured by the discrepancy dummy. All test language coefficients increase by adding the discrepancy dummy. This is caused by filtering out the mother tongue-tested learners and now only catching the non-mother tongue-tested learners and those perform weaker. Comparing coefficient sizes hints at larger test score disadvantage from test language representing school quality - rather than from home language - representing ethnical background. Hence, this is another record in support of the South African school quality discussion.

The third and fourth research questions of the current study asked about the effect of the teacher switching to other languages in order to facilitate understanding during the

TABLE 5: Model results for the discrepancy between language of the test and home language, membership to a language group outside the language of the test.

\begin{tabular}{|c|c|c|c|}
\hline Factor: Constant & 603.3: Coefficient & 12.03: SE & $t$ \\
\hline Female students & 26.45 & 1.37 & $19.31 * * *$ \\
\hline Student age & -7.94 & 0.84 & $9.45^{* * *}$ \\
\hline Student asset scale & 4.57 & 0.46 & $9.93 * * *$ \\
\hline Student asset scale squared & -0.19 & 0.27 & 0.70 \\
\hline School assets & 24.54 & 2.64 & $9.67 * * *$ \\
\hline Discrepancy & -28.94 & 2.81 & $10.3^{* * *}$ \\
\hline Afrikaans test language & -14.77 & 9.86 & 1.5 \\
\hline Afrikaans home language & -25.37 & 6.1 & $4.16^{* * *}$ \\
\hline IsiNdebele test language & -67.30 & 8.32 & $8.09 * * *$ \\
\hline IsiNdebele home language & -33.89 & 5.78 & $5.86 * * *$ \\
\hline IsiXhosa test language & -67.09 & 11.53 & $5.82 * * * *$ \\
\hline IsiXhosa home language & -9.94 & 5.73 & $1.73^{*}$ \\
\hline IsiZulu test language & -68.27 & 11.70 & $5.84 * * *$ \\
\hline IsiZulu home language & -15.03 & 7.04 & $2.13 * *$ \\
\hline Sepedi test language & -96.11 & 10.22 & $9.40 * * *$ \\
\hline Sepedi home language & -37.43 & 6.69 & $5.59 * * *$ \\
\hline Sesotho test language & -71.42 & 9.03 & $7.91 * * *$ \\
\hline Sesotho home language & -19.32 & 5.23 & $3,69 * * *$ \\
\hline Setswana test language & -74.27 & 7.22 & $10,29 * * *$ \\
\hline Setswana home language & -22.93 & 6.15 & $3.73 * * *$ \\
\hline SiSwati test language & -71.83 & 7.9 & $9.09 * * *$ \\
\hline siSwati home language & 21.38 & 6.62 & $3.23 * * *$ \\
\hline Tshivenda test language & -85.34 & 12.48 & $6.84 * * *$ \\
\hline Tshivenda home language & 24.78 & 8.77 & $2.83^{* * *}$ \\
\hline Xitsonga test language & -87.21 & 9.19 & $9.49 * * *$ \\
\hline Xitsonga home language & -25.85 & 6.73 & $3.84 * * *$ \\
\hline
\end{tabular}

$\mathrm{SE}$, Standard error.

***, Indicates $p<0.01$ lesson, as well as the effect of the learner switching to other languages to express their understanding of what was taught. As indicated by Table 6, teachers who switch to other languages resulted in a significant effect of 10.56 lower expected reading score as tested at the $90 \%$ confidence interval. Learners who switch to other languages showed no significant results in the current model.

\section{Discussion}

Grade 4 learners in South African primary schools who participated in prePIRLS 2011 were unable to achieve satisfactory levels of reading competence. The gravity of this finding is exacerbated by the fact that these learners were tested with an easier assessment and in the language of instruction to which they had been exposed during the Foundation Phase of schooling. While the ideals of the LiEP clearly set out to develop African languages, the lack of political will to implement mother tongue-based bilingual education has had far-reaching consequences.

The current study took the form of a secondary analysis of prePIRLS 2011 South African data. Findings illustrate a substantial effect on reading literacy achievement when a discrepancy exists between language of the test and home language when controlling for learner background characteristics. Learners from African language backgrounds are most severely affected when the language of the test and their home language did not coincide and across all African languages reading literacy achievement scores can be expected to decrease substantially when this discrepancy between language of the test and home language exists.

Belonging to a different language group than what the test was written in results in a 29-point decrease in reading literacy achievement, a decrease by almost three quarters of a year for learners who wrote the test in a language outside the broader language group to which they belong. The effect of the teacher who switches language during class to support understanding was significant, yet not so for the effect of the teacher who allows learners to switch language in class to illustrate their understanding. While these findings provide little evidence of the statistically significant effect of codeswitching at the learner level in the current model, it has to be kept in mind that codeswitching practices may still be of educational consequence as it is neither encouraged among learners nor encouraged as part of teacher training practice as stated by work done by Probyn (2009).

Findings from the current analyses are presented against a LiEP background with aims to address issues of equity, equality and the development of all 11 official South African

TABLE 6: Model results for the effect of codeswitching by teachers and students.

\begin{tabular}{lccc}
\hline Factor: Constant & $\begin{array}{c}613.3 \\
\text { Coefficient }\end{array}$ & 13.31: SE & $t$ \\
\hline Teacher switches to other language & -10.56 & 6.32 & $-1.67^{* * * *}$ \\
Students switch to other language & 1.27 & 5.82 & 0.22 \\
\hline SE, Standard error. & & & \\
$* * *$, Indicates $p<0.1$ & & &
\end{tabular}


languages. The complexity of the language in education context of the South African education system, coupled with lack of adequate infrastructure and language resources in specifically disadvantaged communities, continue to contribute to the widening educational gap and poor quality education despite goals of equity and equality. In making a case for the gradual introduction of bilingual education, Edwards and Ngwaru (2011) are of the opinion that teachers will be reluctant to teach in African languages if quality material and resources are not available in these languages. Arguments for and against English as language of instruction were raised in this study. Current evidence allows for speculation that English as language of instruction could be a solution to a complex linguistic problem, but only if learners were acquiring English effectively with support from parents and schools where resources and infrastructure are available. However, the South African reality is one where most African language learners come from impoverished areas and where English remains an unattainable goal, not only as a learning area but also as a means through which knowledge can be accessed (Desai 2001). Where schools apply English as language of instruction, the switch may simply be in adherence to policy. Improved educational outputs are unlikely if other indicators of quality remain the same.

The findings of the current study support ideas expressed by Brock-Utne (2007), who stated that it is not enough to refer to quality education, but to ask what quality education would entail. Against a background of linguistic complexity, the minimum prerequisite should be the type of education that builds on what learners already know and that takes the culture, language and experiences into account. Findings from the current study provide clear evidence that African children stand to be disadvantaged the most when a strong mother tongue base has not been developed in the early years and when education for these children is only available through a medium of instruction other than the mother tongue. In cases where it is not practically possible to have learners taught in their mother tongue, the current study provides evidence that exposure to a language that at least shares linguistic similarities to the home language could have a positive effect. The exposure to and testing of learners in languages other than home language results in nothing more than what Desai (2001) referred to as 'incomprehensible education'. While the development of African languages should be paramount in the implementation of the LiEP, success can only follow if greater currency is afforded to African languages in society, business and government and when the speakers of African languages assert their rights and greater currency for their languages.

\section{Acknowledgements Competing interests}

The authors declare that they have no financial or personal relationships which may have inappropriately influenced them in writing this article.

\section{Authors' contributions}

S.v.S. conceptualised the manuscript and performed the literature review. R.B. made conceptual contributions and performed initial analysis. A.B. performed additional analyses.

\section{References}

Admiraal, W., Westhoff, G. \& de Bot, K., 2006, 'Evaluation of bilingual secondary education in the Netherlands: Learners' language proficiency in English', Educational Research and Evaluation 12(1), 75-93. http://dx.doi.org/10.1080/ 13803610500392160

Ahmed, R. \& Sayed, Y., 2009, ‘Promoting access and enhancing education opportunities? The case of 'no-fees schools' in South Africa', Compare: A Journal of International and Comparative Education 39(23), 203-218.

Andrabi, T., Das, J., Khwaja, A.I. \& Zajonc, T., 2011, 'Do value added estimates add value? Accounting for learning dynamics', American Economic Journal: Applied Economics 3(3), 29-54.

Bergbauer, A.B., 2015, 'The economics of education in South Africa - Analysis of prePIRLS 2011. Deprivation is not destiny - How socioeconomics and school quality shape literacy success', Unpublished masters dissertation, Georg-August University, Göttingen.

Brock-Utne, B., 2007, 'Language of instruction and learner performance: New insights from research in Tanzania and South Africa', International Review of Education 53 509-530. http://dx.doi.org/10.1007/s11159-007-9065-9

Carlo, M.A., August, D., McLaughlin, B., Snow, C.E., Dressler, C., Lippman, D.N. et al., 2004, 'Closing the gap: Addressing the vocabulary needs of English-language learners in bilingual and mainstream classrooms', Reading Research Quarterly 39(2), 188-215. http://dx.doi.org/10.1598/RRQ.39.2.3

Census, 2011, 'Statistical release', viewed 3 October 2014, from www.statssa.gov.za/ census2011/Product/Census_2011_Census_in_brief.pdf

Department of Education, South Africa, 1997, December 19. Government gazette no. 18546.

Deming, D.J., Hastings, J.S., Kane, T.J. \& Staiger, D.O., 2014, 'School choice, school quality, and postsecondary attainment', The American Economic Review 104(3), 991-1013. http://dx.doi.org/10.1257/aer.104.3.991

Desai, Z., 2001, 'Multilingualism in South Africa with particular reference to the role of African languages in Education', International Review of Education 47(3-4), 323-339. http://dx.doi.org/10.1023/A:1017957927500

De Wet, C., 2002, 'Factors influencing the choice of English as language of learning and teaching (LoLT) - A South African perspective', South African Journal of Education 22(2), 119-124.

Droop, M. \& Verhoeven, L., 2003, 'Language proficiency and reading ability in firstand second-language learners', Reading Research Quarterly 38(1), 78-103. http:// dx.doi.org/10.1598/RRQ.38.1.4

Edwards, V. \& Ngwaru, J.M., 2011, 'Multilingual education in South Africa: The role of publishers', Journal of Multilingual and Multicultural Development 32(5), 435-450. http://dx.doi.org/10.1080/01434632.2011.592192

Evans, W.N. \& Schwab, R.M., 1995, 'Finishing high school and starting college: Do Catholic schools make a difference?', The Quarterly Journal of Economics 110 (4), 941-974.

Finlayson, R. \& Madiba, M., 2002, 'The intellectualisation of the indigenous languages of South Africa: Challenges and prospects', Language Planning 3(1), 40-61. http:// dx.doi.org/10.1080/14664200208668036

Grant, R.A. \& Wong, S.D., 2003, 'Barriers to literacy for language-minority learners: An argument for change in the literacy education profession', Journal of Adolescent and Adult Literacy 46(5), 386-394. http://dx.doi.org/10.1598/JAAL.46.5.2

Hauser, R.M., 1994, 'Measuring socioeconomic status in studies of child development', Child Development 65(6), 1541-1545. http://dx.doi.org/10.2307/1131279

Heugh, K., 2002, 'The case against bilingual and multilingual education in South Africa: Laying bare the myths', Perspectives in Education 20(1), 171-196.

Howie, S.J., Venter, E. \& Van Staden, S., 2008, 'The effect of multilingual policies on performance and progression in reading literacy in South African primary schools', Educational Research and Evaluation 14(6), 551-560. http://dx.doi.org/ 10.1080/13803610802576775

Howie, S.J., Venter, E., Van Staden, S., Zimmerman, L., Long, C., Scherman, V. et al., 2009, PIRLS 2006 summary report: South African children's reading literacy achievement, Centre or Evaluation and Assessment, Pretoria.

Kamwangamalu, N.M., 2003, 'Social change and language shift: South Africa', Annua Review of Applied Linguistics 23, 225-242. http://dx.doi.org/10.1017/S02671905 03000291

Koda, K., 2007, 'Reading and language learning: Crosslinguistic constraints on second language reading development', Language Learning 57(Suppl. 1), 1-44. http:// dx.doi.org/10.1111/0023-8333.101997010-i1

Motala, S., 2001, 'Quality and indicators of quality in South African education: A critical appraisal', International Journal of Educational Development 21, 61-78. http://dx.doi.org/10.1016/S0738-0593(00)00014-6 
Motala, S., 2006, 'Education resourcing in post-apartheid South Africa: The impact of finance equity reforms in public schooling, Perspectives in Education 24(2), 79-93. http://dx.doi.org/10.1257/app.3.3.29

Mothata, M.S. \& Lemmer, E.M., 2002, 'The provision of education for minorities in South Africa', South African Journal of Education 22(2), 106-112.

Mullis, I.V.S., Kennedy, A.M., Martin, M.O. \& Sainsbury, M., 2004, PIRLS 2006 assessment framework and specifications, TIMSS and PIRLS International Study Center, Boston College, Boston, MA.

Mullis I.V.S., Martin, M.O., Kennedy, A.M., Trong, K.L. \& Sainsbury, M., 2009, PIRLS 2011 assessment framework, TIMSS and PIRLS International Study Center, Boston College, Boston, MA.

Mullis, I.V.S., Martin, M.O., Kennedy, A.M. \& Foy, P., 2007, PIRLS 2006 internationa report: IEA's study of reading literacy achievement in primary schools, Chestnut Hill, Boston College, Boston, MA.

Mullis, I.V.S., Martin, M.O., Foy, P. \& Drucker, K.T., 2012, PIRLS 2011 international results in reading, Boston College, Chestnut Hill, MA.

Ncoko, S.O.S., Osman, R. \& Cockroft, K., 2000, 'Codeswitching among multilingua learners in primary schools in South Africa: An exploratory study', International Journal of Bilingual Education and Bilingualism 3(4), 225-241.

Nyika, N., 2009, 'Language complaints as an instrument of language rights activism: The case of PanSALB as a guardian of the right to mother-tongue education" Language Matters 40(2), 239-260. http://dx.doi.org/10.1080/10228190903 188583
Pretorius, E., 2002, 'Reading ability and academic performance in South Africa: Are we fiddling while Rome is burning?', Language Matters: Studies in Language in Africa 33(1), 169-196. http://dx.doi.org/10.1080/10228190208566183

Pritchett, D. \& Filmer, L.H., 2001, 'Estimating wealth effects without expenditure data Or tears. An application to educational enrollment in states of India', Demography 38(1), 115-132.

Probyn, M., 2001, 'Teacher voices: Teachers reflections on learning and teaching through the medium of English as an additional language in South Africa', International Journal of Bilingual Education and Bilingualism 4(4), 249-266. http://dx.doi.org/10.1080/13670050108667731

Probyn, M., 2009, “'Smuggling the vernacular into the classroom": Conflicts and tensions in classroom codeswitching in township/rural schools in South Africa', International Journal of Bilingual Education and Bilingualism 12(2), 123-136. http://dx.doi.org/10.1080/13670050802153137

Scott-Jones, D., 1984, 'Family influences on cognitive development and schoo achievement', Review of Research in Education 11, 259-304.

Taylor, N, 2007, 'Equity, efficiency and the development of South African schools', in T. Townsend (ed.), International handbook of school effectiveness and improvement, pp. 523-540, Springer, Dordrecht.

Van Staden, S., 2010, 'Reading between the lines: Contributing factors that affect Grade 5 learner reading performance', Unpublished PhD thesis, University of Pretoria. 